\title{
CONTROL OF CATALYTIC HYDROTREATING SELECTIVITY WITH AMMONIA
}

\author{
Report for January 1, 1992 to March 31, 1992
}

Report No.:

DOE/PC89775-8

Grant No.:

DE-FG22-89PC89775

Submitted by:

\section{Charles N. Satterfield}

Chung M. Lee

\section{DISCLAIMER}

This report was prepared as an account of work sponsored by an agency of the United States This report was prepared anernment nor any agency thereof, nor any of their Government. Neither the United States Gover implied, or assumes any legal liability or responsiemployees, makes any warranty, express or implied, or assunformation, apparatus, product, or bility for the accuracy, completeness, or usefulness of any information, apparalus, prodects or process disclosed, or represents that its use would not in or service by trade name, trademark, ence herein to any specific commercial product, pronstitute or imply its endorsement, recornmanufacturer, or otherwise does not necessarily constitute or imply inency thereof. The views mendation, or favoring by the United States Government or any agency thereof. The the and opinions of authors expressed herein do

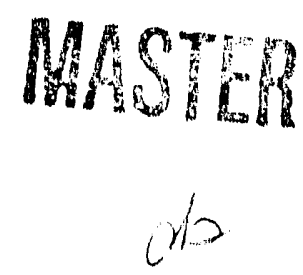




\section{Summary}

The hydrogenation of naphthalene in the presence of 0,24 , or $48 \mathrm{kPa}$ of ammonia derived from propyl amine was studied during the hydrodeoxygenation (HDO) of dibenzofuran (DBF). A new sample of sulfided $\mathrm{NiMo} / \mathrm{Al}_{2} \mathrm{O}_{3}$ catalyst at $360^{\circ} \mathrm{C}, 6.9 \mathrm{MPa}$ total $\mathrm{H}_{2}$ pressure in a vapor phase tubular reactor was used. As a base-line the HDO of DBF was also studied in the absence of both naphthalene and ammonia. Ammonia inhibited both the HDO of dibenzofuran and the hydrogenation of naphthalene. The addition of ammonia may not be suitable if a high conversion of HDO is desired. 


\section{Experimental}

All runs were made with feeds consisting of $0.25 \mathrm{~mol} / \mathrm{L}$ of naphthalene $(99+\%$ pure, Aldrich) and $0.035 \mathrm{~mol} / \mathrm{L}$ of dibenzofuran (99\% pure, Aldrich), except when baseline runs were made in the absence of both naphthalene and ammonia. Propylamine ( $98 \%$ pure, Aldrich) when desired was added at concentrations of $0.24 \mathrm{~mol} / \mathrm{L}$ or 0.48 $\mathrm{mol} / \mathrm{L}$ to generate in situ ammonia partial pressures of $24 \mathrm{kPa}$ or $48 \mathrm{kPa}$ in the reactor. Hydrogen sulfide partial pressure of $12 \mathrm{kPa}$, for maintaining the sulfided state of the catalyst, was generated in situ in the reactor by the addition of $0.12 \mathrm{~mol} / \mathrm{L}$ of 1 dodecanethiol ( $98 \%$ pure, Aldrich) to the feed. The solvent was essentially a $\mathrm{C}_{16} \mathrm{n}$ paraffin consisting of about $93 \% \mathrm{C}_{16} \mathrm{H}_{34}$ and $7 \%$ other paraffins, mostly $\mathrm{C}_{14} \mathrm{H}_{30}$ and $\mathrm{C}_{18} \mathrm{H}_{38}$. As in previous work liquid samples of the reactor effluent were collected downstream from a low-pressure phase separator, and analyzed on a Perkin-Elmer Sigma 1B gas chrornatograph equipped with dual flame ionization detectors. Concentrations of the products were related to the starting liquid feed. Carbon mass balances on total products compared to naphthalene disappearance exceeded $96 \%$. Separation of reaction species was accomplished by using a Supelco SPB-35 (30 meters, $0.25 \mathrm{~mm} \mathrm{ID,} 0.25 \mu \mathrm{m}$ ) column and a Supelcowax 10 ( 30 meters, $0.25 \mathrm{~mm} \mathrm{ID,} 0.25 \mu \mathrm{m})$ column.

\section{$\underline{\text { Results }}$}

Data are presented in two alternate forms. In order to make comparisons against the base-line operation in the absence of naphthalene, \% conversion and selectivities from the HDO of DBF are plotted versus LHSV. For other comparisons data are 
plotted versus space time relative to naphthalene.

Figure 1 shows the extent of HDO versus LHSV. HDO of dibenzofuran is not affected by the presence of naphthalene, but ammonia does inhibit HDO. Interestingly, the additional ammonia from $24 \mathrm{kPa}$ to $48 \mathrm{kkPa}$ had marginally less inhibition. Although the addition of ammonia inhibited the hydrogenation of naphthalene, its presence caused more dicyclohexyl to form relative to the amount of cyclohexylbenzene formed, see Figure 1a.

Figure 2 shows the effect of ammonia on the HDO of dibenzofuran during the hydrogenation of naphthalene, as plotted versus space time. The products from the HDO of dibenzofuran have been identified by LaVopa and Satterfield (1987). In agreement with the earlier work, under present reaction conditions dibenzofuran was the only observed oxygenated species, i.e., no intermediates containing oxygen were observed. Double-ring deoxygenated products consisted of biphenyl, cyclohexylbenzene, and dicyclohexyl. Single-ring deoxygenated products consisted of methylcyclohexane, benzene, cyclohexane, methylcyclopentane, and pentane. Since the HDO of DBF exhibits first-order behavior, the lines in Figure 2 represent linear regression lines.

Figure 3 shows a plot of the fraction of initial dibenzofuran (DBF) fed into the reactor that was converted to single-ring products versus LHSV for four feeds studied. Figure 4 is a similar plot for double-ring products. These figures show that ammonia does indeed inhibit the HDO of DBF as evident by the decreasing concentrations of single-ring and double-ring products. The presence of naphthalene mildly affects product selectivity in the HDO of DBF. Its presence slightly increased the selectivity to double- 
ring products while hampering the formation of single-ring products. Thus the net effect of naphthalene on the overall HDO of DBF is negligible.

Figure 5 shows a plot of the selectivity to single-ring products (fraction of total deoxygenated products that is single-ring). The selectivity for the feed containing DBF only (no naphthalene or ammonia, $\mathrm{H}_{2} \mathrm{~S}$ is present) is approximately $71 \%$ single-ring products. This is in good agreement with the selectivity results observed by LaVopa. The presence of naphthalene slightly lowered the selectivity to single-ring products. The addition of $24 \mathrm{kPa}$ of ammonia had little effect over the presence of naphthalene, but addition of $48 \mathrm{kPa}$ ammonia lowered the selectivity to single-ring proucts even more.

Figures 6 and 7 show the fraction of DBF converted to single-ring and double-ring products in the form of space-time plots. The addition of ammonia inhibited the formation of both single-ring and double-ring products. Figure 8 shows the selectivity to single-ring products which is defined as the fraction of total deoxygenated products that are single-ring products. The addition of $24 \mathrm{kPa}$ of ammonia seems to have no effect on the selectivity, but the addition of $48 \mathrm{kPa}$ of ammonia seems to reduce the selectivity to single-ring products at lower space times. In our earlier work we found single-ring products to be about $72 \%$ of total deoxygenated products, which is in general agreement with the values in Figure 8.

Figure 9 shows the inhibition of the hydrogenation of naphthalene by the addition of ammonia, which occurred simultaneously with the HDO reactions. Figure 10 shows the increase in selectivity to tetralin over decalins by the addition of ammonia. This is similar to the selectivity effect we observed in mixtures of naphthalene and quinoline. 
Figure 11 shows first order hydrogenation rate constants for naphthalene to tetralin and for tetralin to decalins. The inhibition of hydrogenation seems to taper off as ammonia concentration is increased $24 \mathrm{kPa}$ to $48 \mathrm{kPa}$.

\section{Discussion}

The addition of ammonia inhibits the HDO of dibenzofuran more strongly than the HDN of quinoline. The addition of $24 \mathrm{kPa}$ of ammonia resulted in a fractional loss of HDO activity of $65 \%$. The further addition of ammonia to $48 \mathrm{kPa}$ had only a little more inhibition; the fractional loss of activity was $68 \%$. We hypothesize that dibenzofuran is not as strongly adsorbed as quinoline, so that ammonia more readily competes with DBF for adsorption sites. Thus, the addition of ammonia prevents c implete HDO of DBF even at the highest space times studied. We conclude that the arldition of ammonia may not be suitable when emphasis is on HDO reactions. As long as there are intermediate nitrogen-containing products from the HDN of quinoline, F(I)O of dibenzofuran is suppressed. Therefore, all nitrogen-containing species, inc luding ammonia, may have to be removed from the system before HDO can eff ctively progress. Thus during hydrotreating, while the addition of ammonia may help in reducing the hydrogenation of aromatics during the HDN reactions, it may be necus sary to remove the ammonia before HDO to achieve the level of HDO desired.

Figure 12 shows that the HDO of dibenzofuran has little effect on the hydrogenation of naphthalene. Thus the inhibition that occurs with the addition of ammo ia is caused by the ammonia and not by dibenzofuran or its HDO products. A 
comparison of the first order rate constants from Figure 10 to those in Figure 11 shows that there is more inhibition of the hydrogenation of naphthalene caused by ammonia in the naphthalene/dibenzofuran system than in the naphthalene/quinoline system.

Without the presence of strongly adsorbed nitrogen compounds such as quinoline and its partially denitrogenated products, ammonia readily inhibits the hydrogenation of naphthalene. 


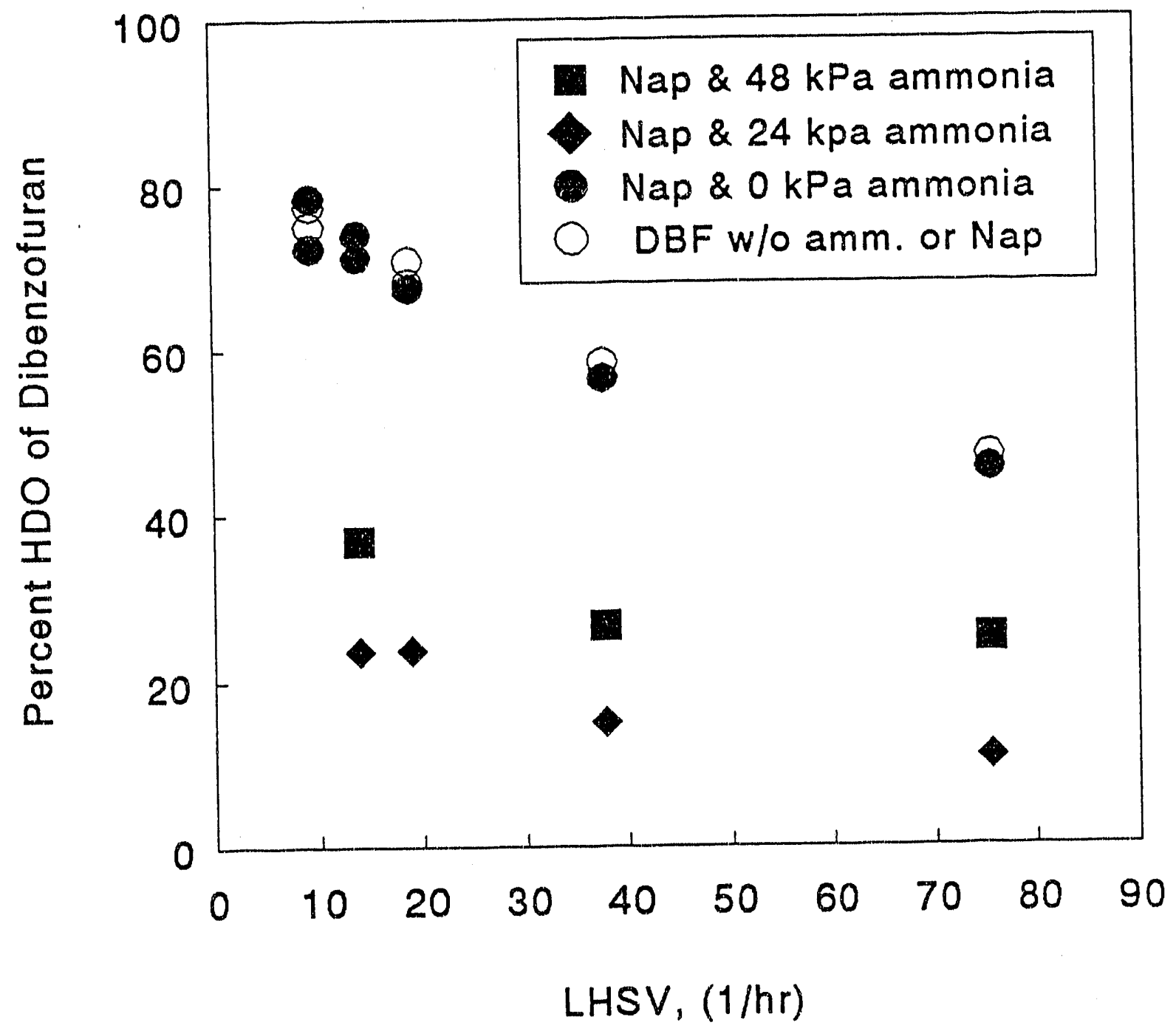

Figure 1 Effect of $\mathrm{NH}_{3}$ on $\mathrm{HDO}$ of dibenzofuran 


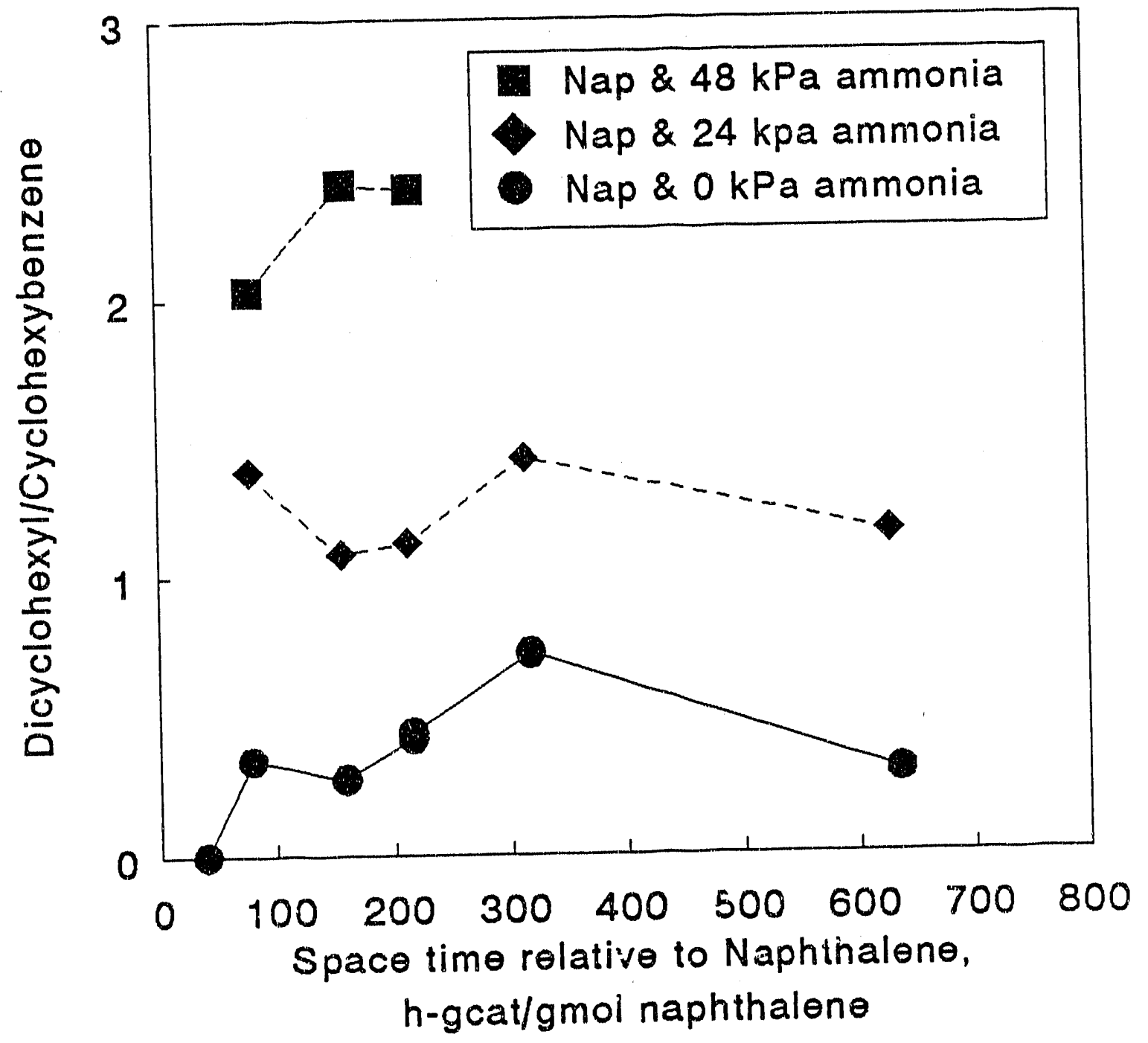

Figure 1a Ammonia increases the ratio of dicyclohexyl to cyclohexylbenzene 


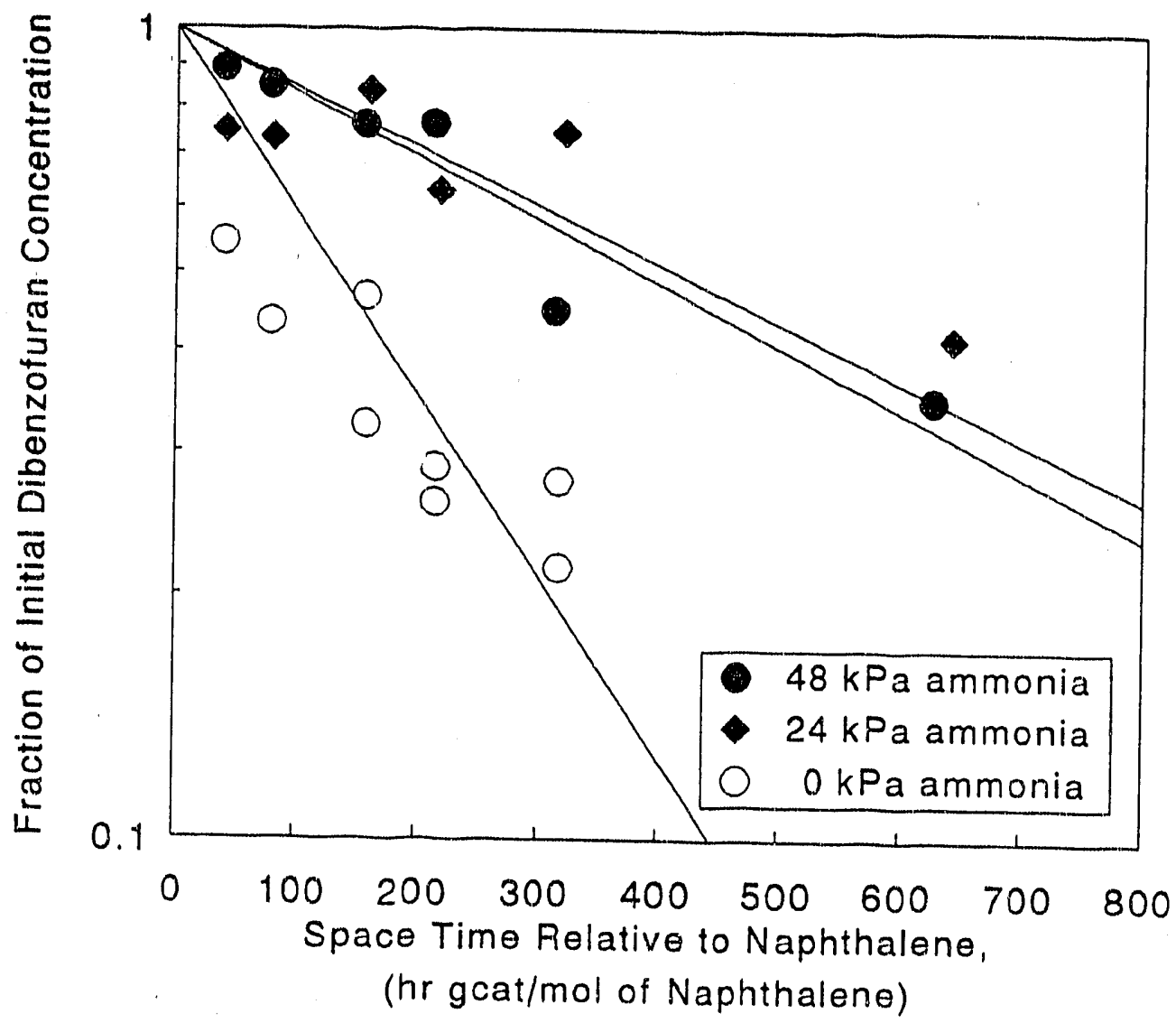

Figure 2

Hydrodeoxygenation of dibenzofuran during the hydrogenation of naphthalene without ammonia and with 24 and $48 \mathrm{kPa}$ of ammonia $\left(360^{\circ} \mathrm{C}\right.$, 6.9 MPa). 


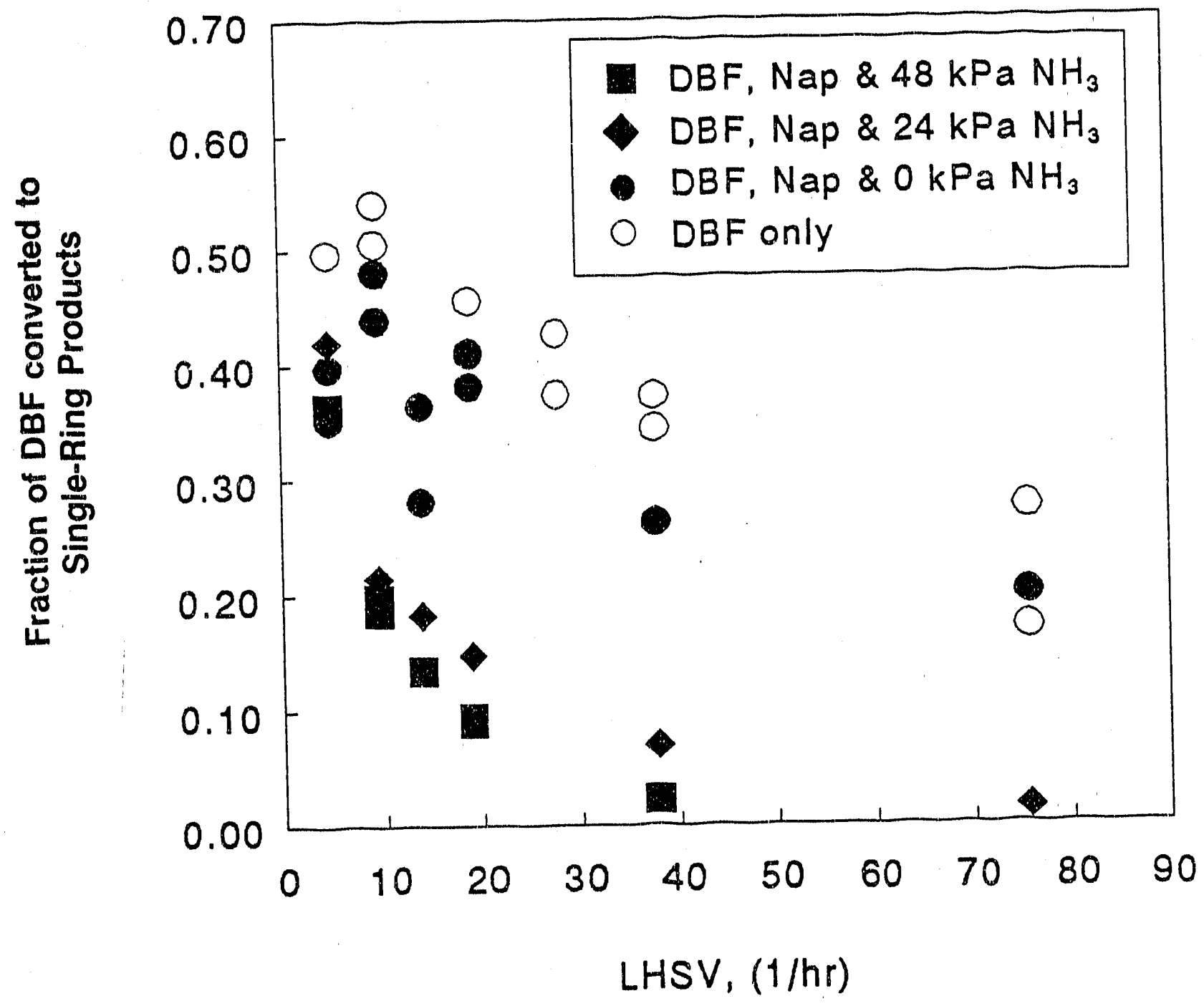

Figure 3

Effect of $\mathrm{NH}_{3}$ on fraction of single ring products from the HDO of DBF 


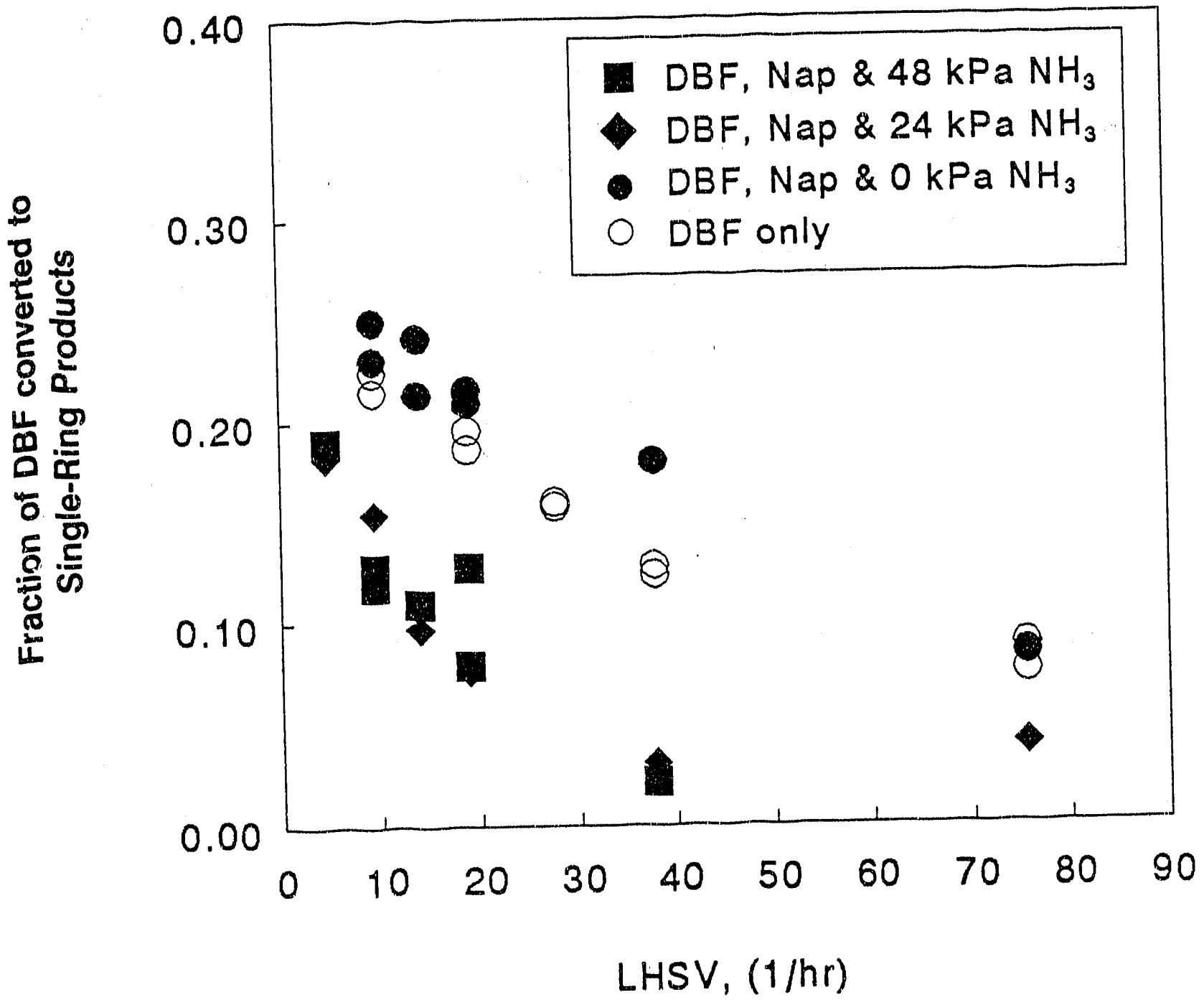

Figure 4

Effect of $\mathrm{NH}_{3}$ on fraction of double ring products from the HDO of DBF 


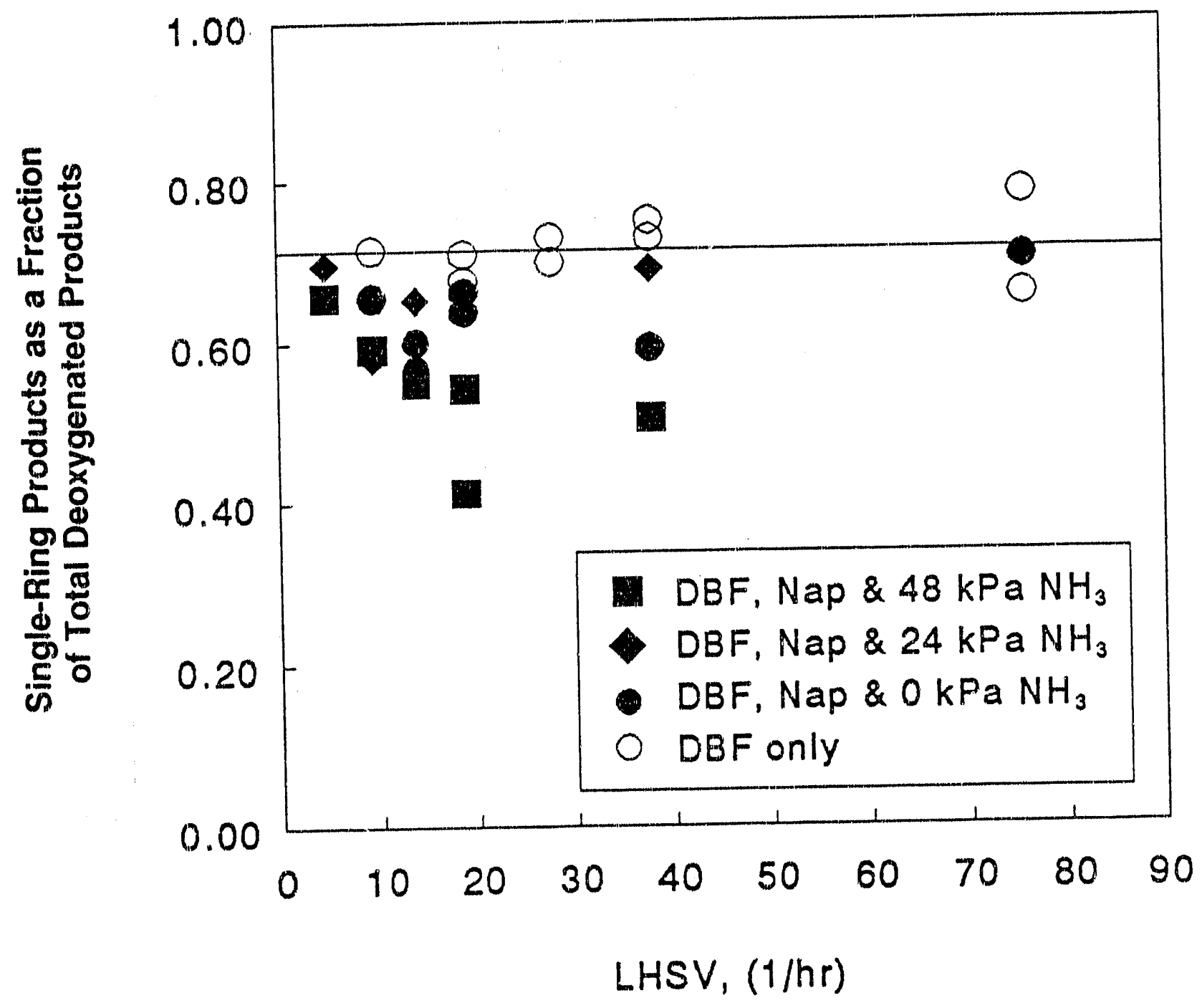

Figure 5

Effect of $\mathrm{NH}_{3}$ on Selectivity 


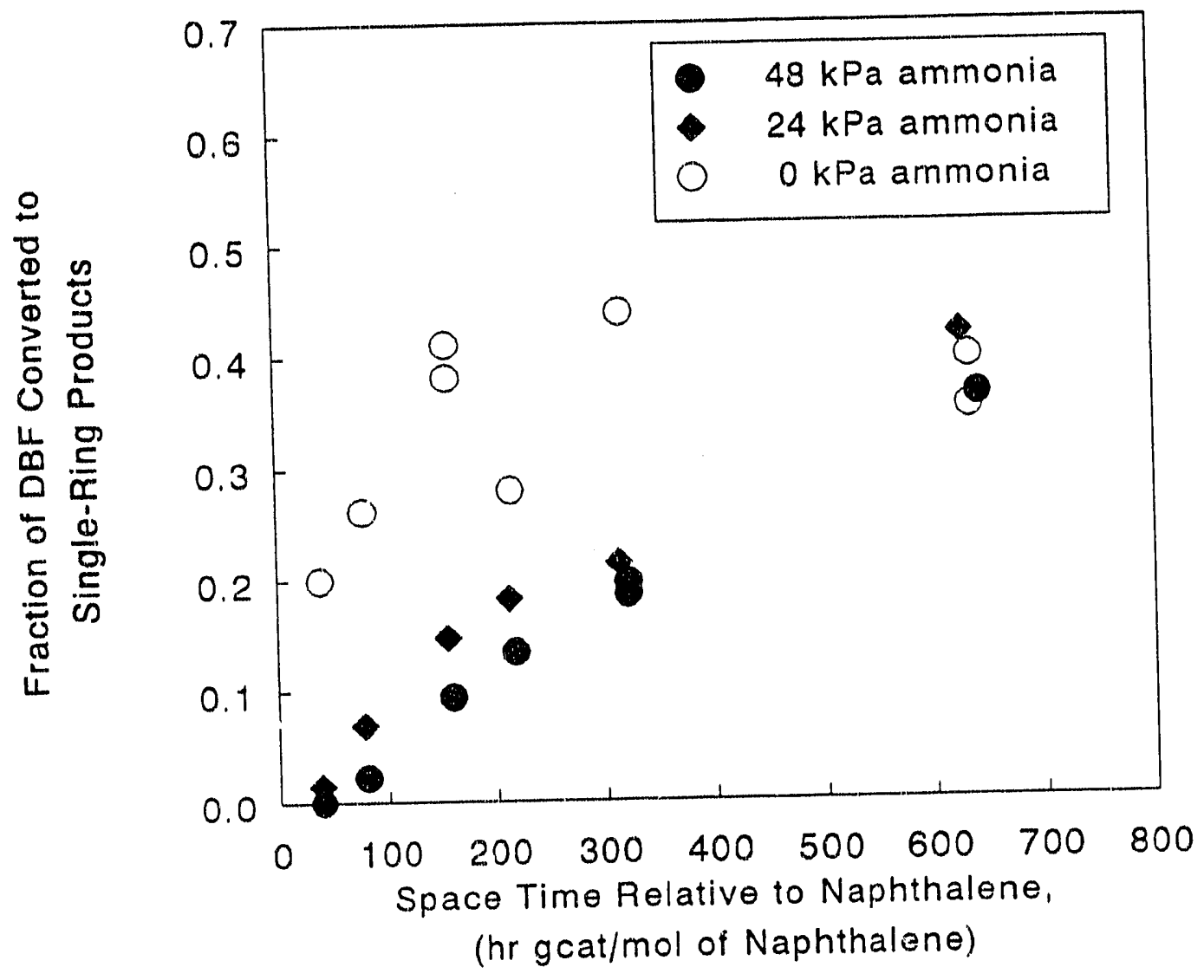

Figure 6

The effect of ammonia on deoxygenated single-ring products from the $\mathrm{HDO}$ of dibenzofuran $\left(360^{\circ} \mathrm{C}\right.$, 6.9 MPa). 


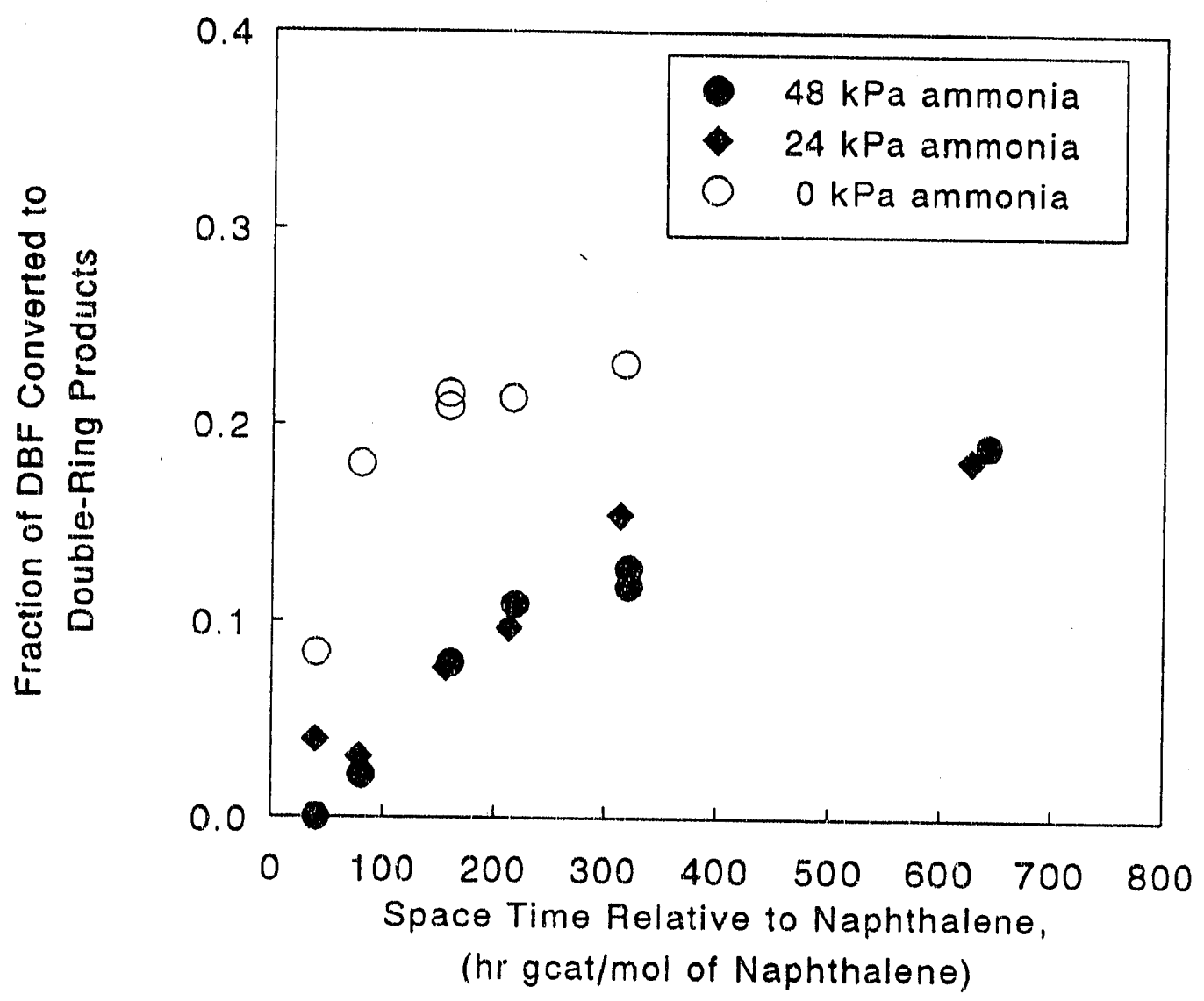

Figure 7

The effect of ammonia on deoxygenated doublering products from the HDO of dibenzofuran $\left(360^{\circ} \mathrm{C}, 6.9 \mathrm{MPa}\right)$. 


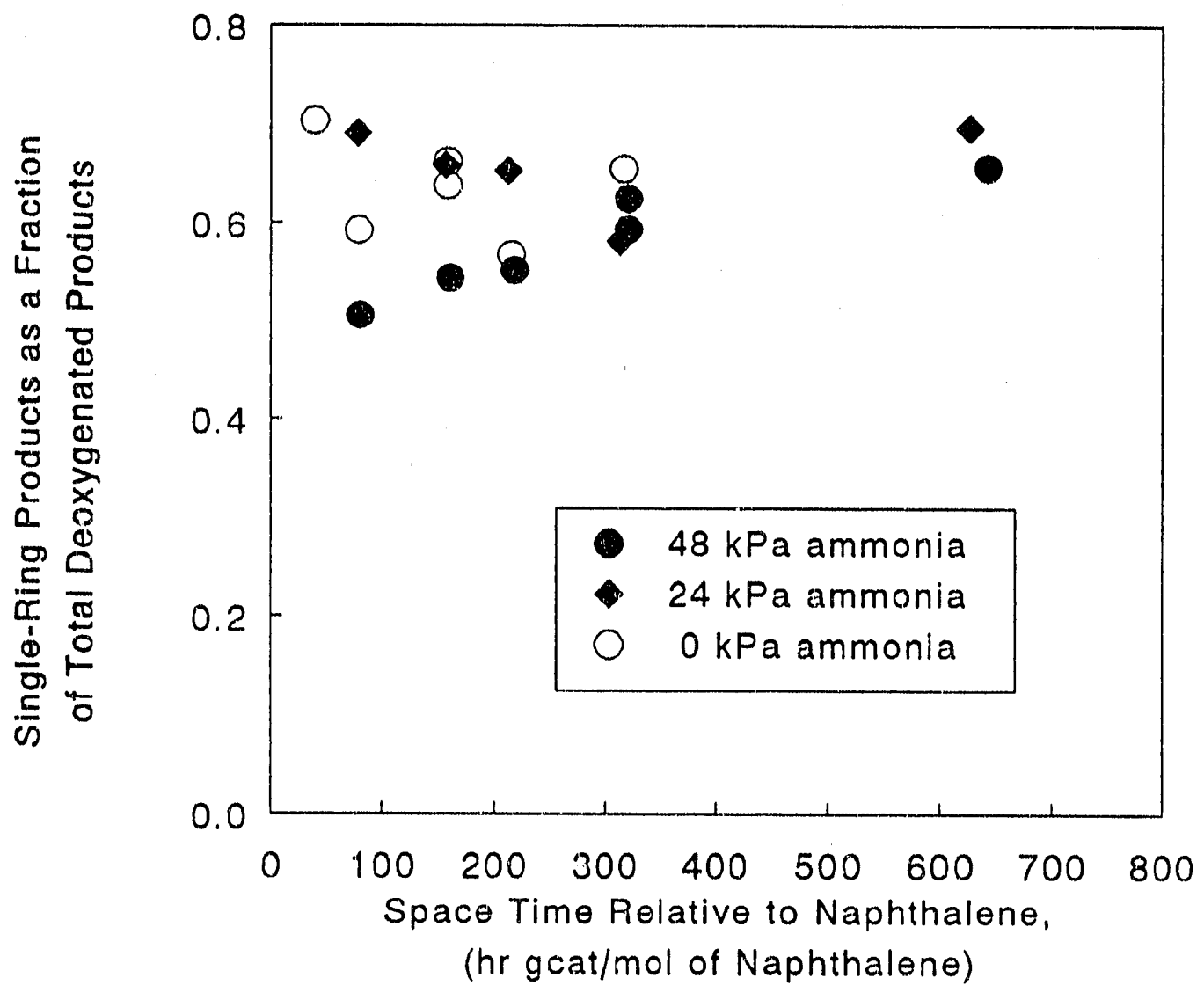

Figure 8

Single-ring products as a fraction of total deoxygenated products are not affected by ammonia concentration $\left(360^{\circ} \mathrm{C}, 6.9 \mathrm{MPa}\right)$. 


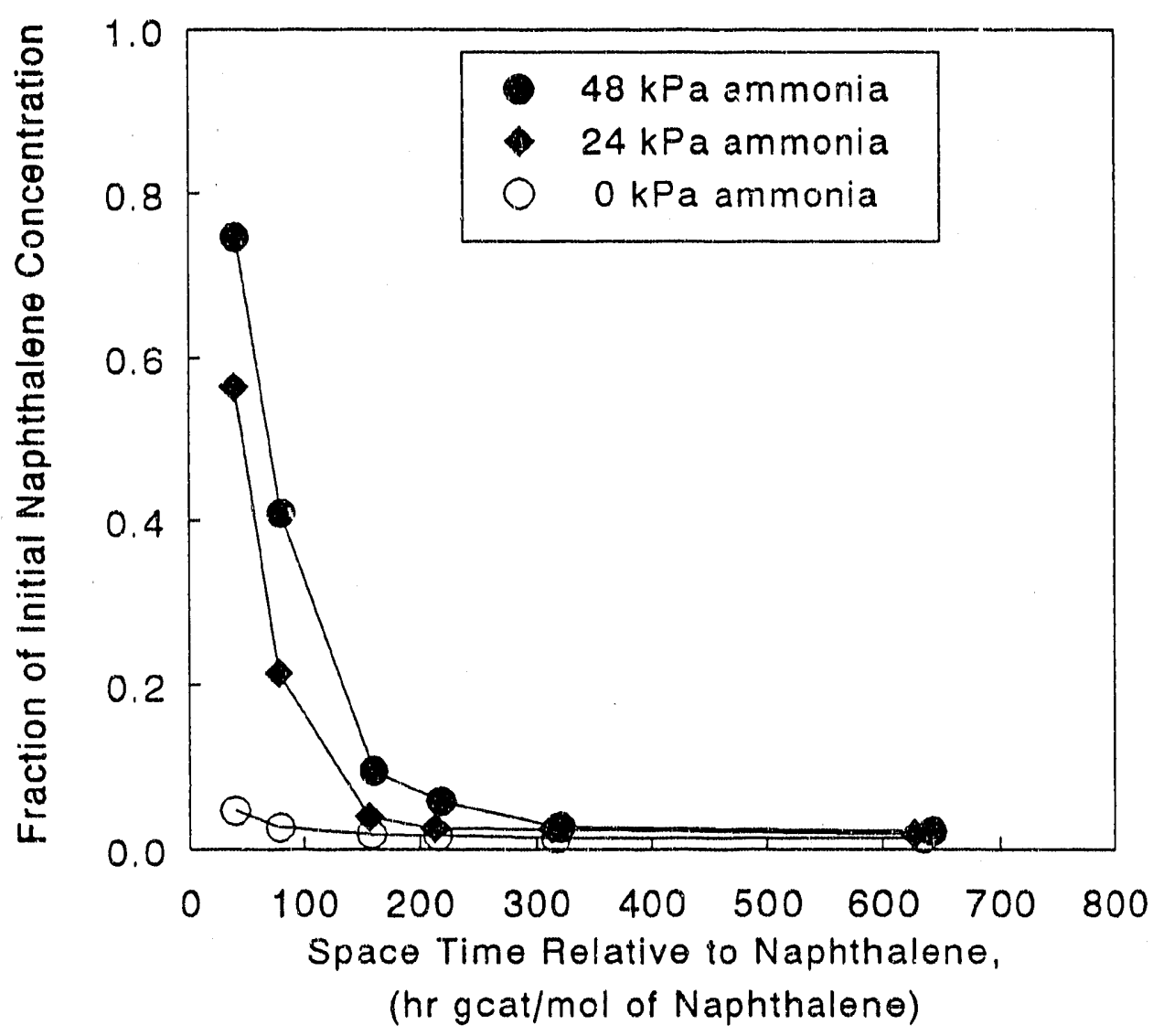

Figure 9

The effect of ammonia on the hydrogenation of naphthalene during the HDO of dibenzofuran $\left(360^{\circ} \mathrm{C}, 6.9 \mathrm{MPa}\right)$. 


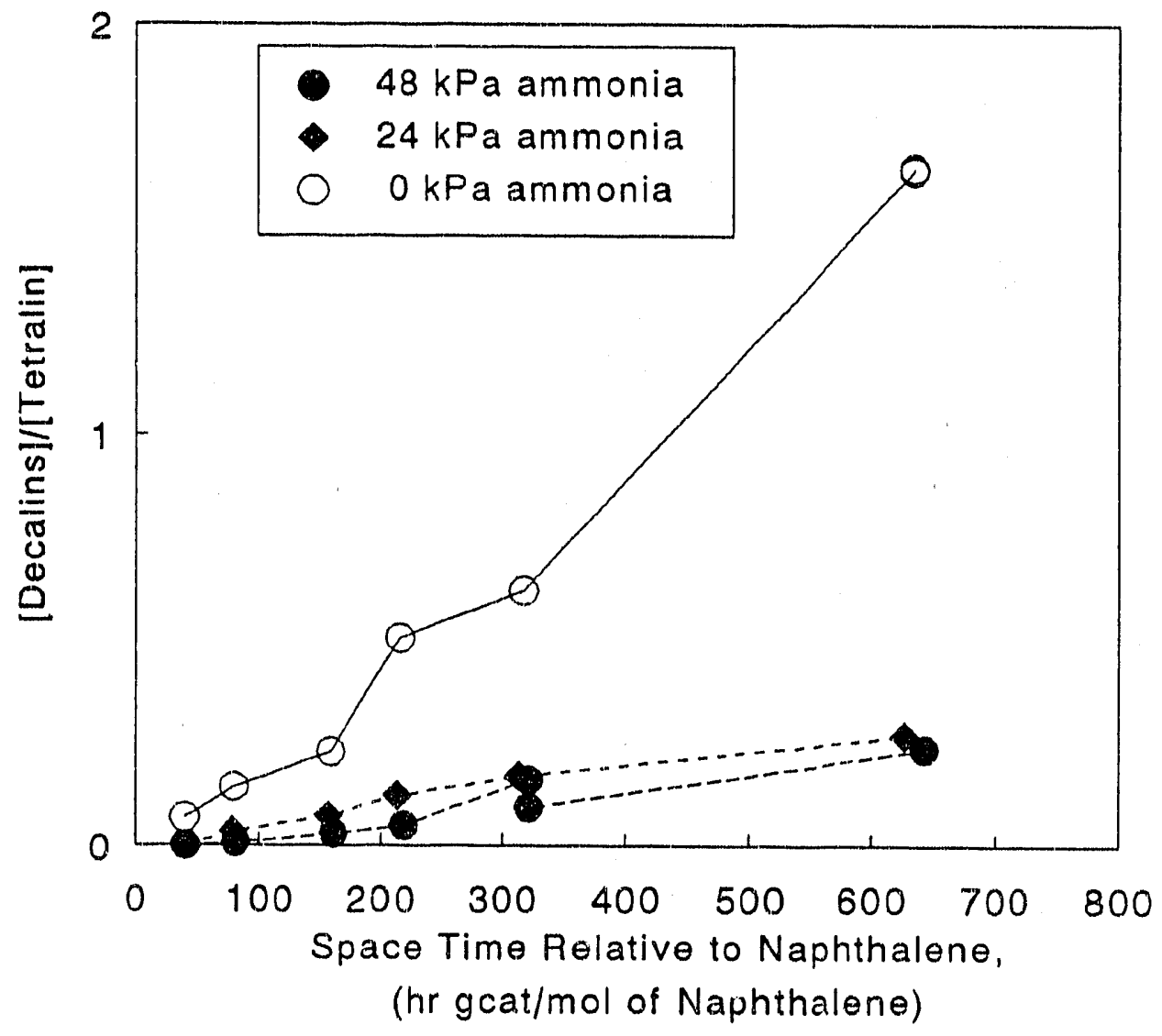

Figure 10 Ammonia increases the selectivity of tetralin $\left(360^{\circ} \mathrm{C}\right.$, $6.9 \mathrm{MPa})$. 


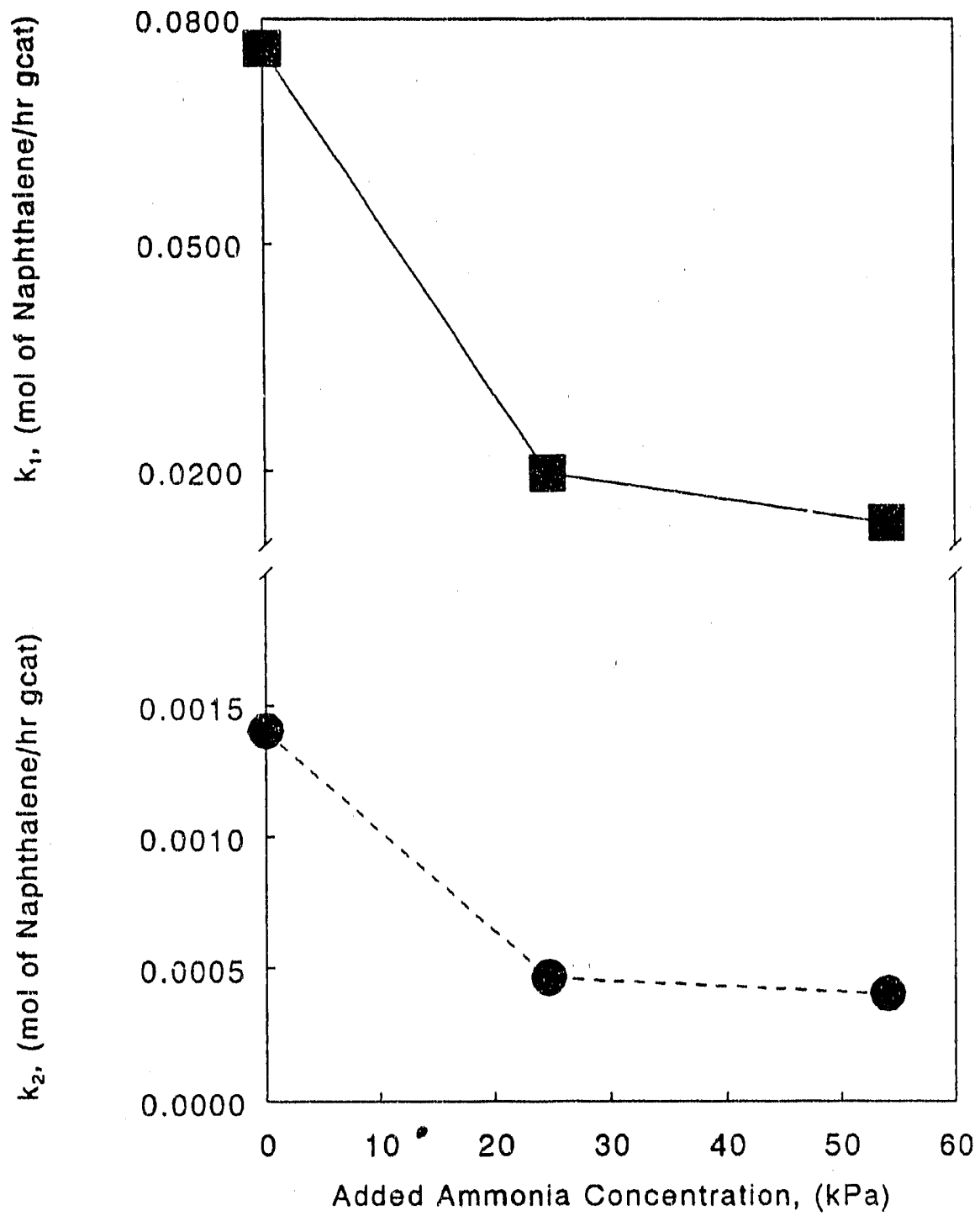

Figure 11 First order hydrogenation rate constants for naphthalene to tetralin, $k_{1}$, and for tetralin to decalins, $k_{2}$, versus ammonia concentration $\left(360^{\circ} \mathrm{C}, 6.9 \mathrm{MPa}\right)$. 


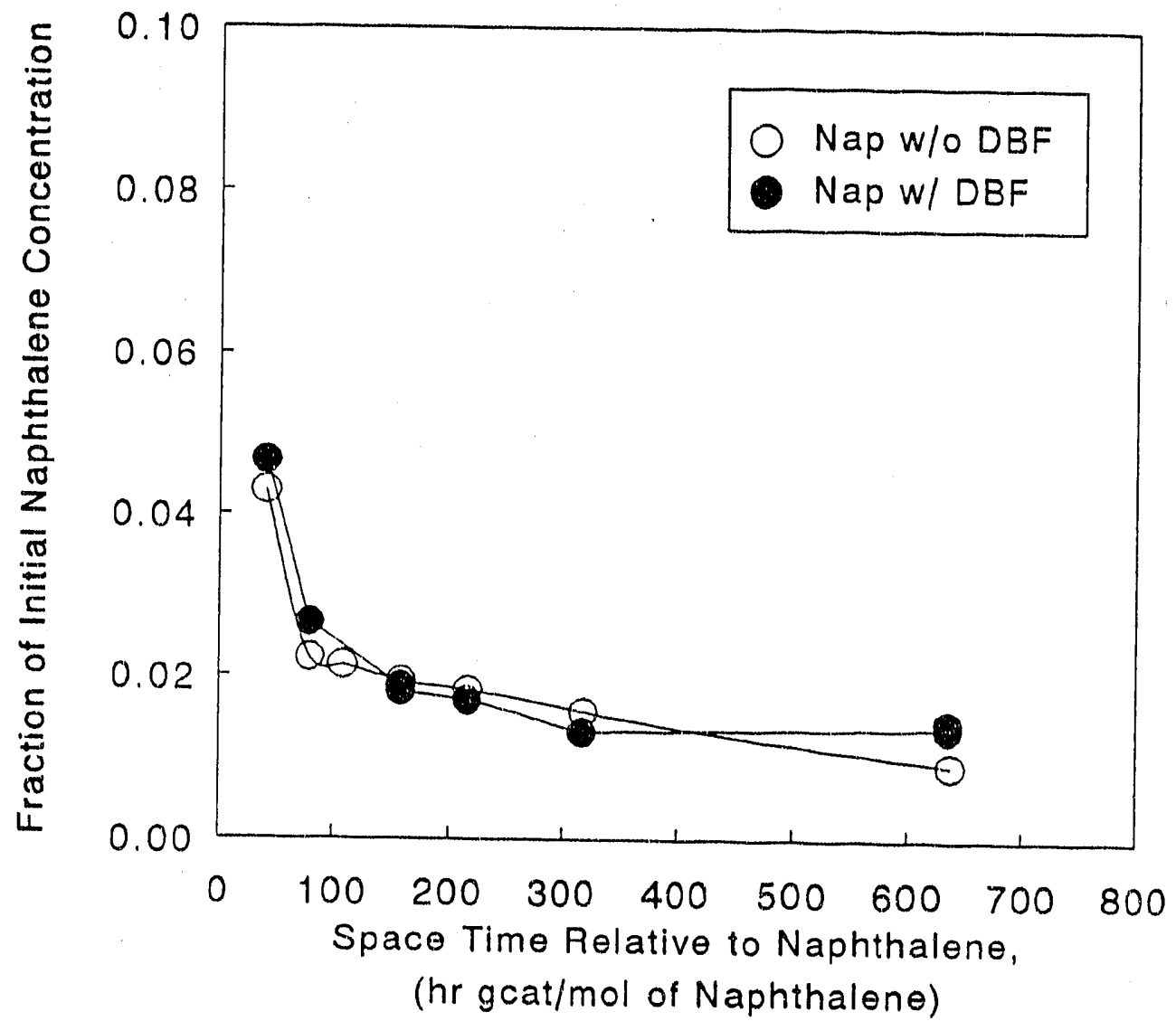

Figure 12 The effect of dibenzofuran on the hydrogenation of naphthalene $\left(360^{\circ} \mathrm{C}, 6.9 \mathrm{MPa}\right)$. 


$$
\begin{aligned}
& \\
& \text { DATE } \\
& \text { FILMED } \\
& 8127192
\end{aligned}
$$


